\title{
Overlook of current chemical vapor deposition-grown large single-crystal graphene domains
}

\author{
Kyung Tae Park, Taehoon Kim and Chong Rae Park* \\ Carbon Nanomaterials Design Laboratory, Global Research Laboratory, Research Institute of Advanced Materials, and Department of \\ Materials Science and Engineering, Seoul National University, Seoul 151-744, Korea
}

\author{
Article Info \\ Received 21 March 2014 \\ Accepted 25 June 2014 \\ *Corresponding Author \\ E-mail: crpark@snu.ac.kr \\ Tel: $+82-2-880-8030$

\section{Open Access} \\ DOI: http://dx.doi.org/ \\ 10.5714/CL.2014.15.3.151 \\ This is an Open Access article distributed \\ under the terms of the Creative Commons \\ Attribution Non-Commercial License \\ (http://creativecommons.org/licenses/ \\ by-nc/3.0/) which permits unrestricted \\ non-commercial use, distribution, and \\ reproduction in any medium, provided \\ the original work is properly cited.
}

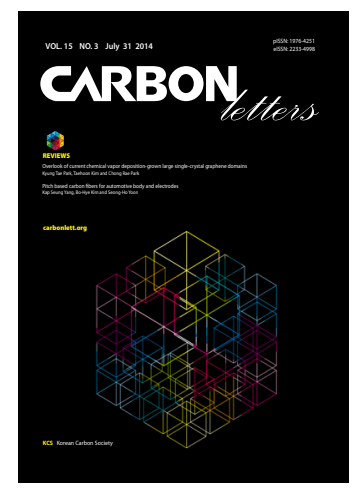

http://carbonlett.org

pISSN: 1976-4251

elSSN: 2233-4998

Copyright $\odot$ Korean Carbon Society

\begin{abstract}
Exceptional progress has been made with chemical vapor deposition (CVD) of graphene in the past few years. Not only has good monolayer growth of graphene been achieved, but large-area synthesis of graphene sheets has been successful too. However, the polycrystalline nature of CVD graphene is hampering further progress as graphene property degrades due to presence of grain boundaries. This review will cover factors that affect nucleation of graphene and how other scientists sought to obtain large graphene domains. In addition, the limitation of the current research trend will be touched upon as well.
\end{abstract}

Key words: chemical vapor deposition, graphene, single-crystal, seeded growth

\section{Introduction}

Graphene-a single atomic layer of graphite-has been in the scientific spotlight ever since its discovery in 2004 [1]. After a decade of substantial research, its electrical, optical, and mechanical properties are now better understood. In addition, various graphene-based labscale devices, such as electrodes [2-4], field-emitting devices [5,6], and sensors [7,8], have been successfully fabricated. Although these accomplishments show a glimpse of the promising technology graphene could bring in the future, there are still many hurdles that needs to be overcome before graphene becomes incorporated into our everyday devices.

Various methods have been assessed in an effort to produce graphene on an industrial scale. These include chemical exfoliation [9], epitaxial growth on $\mathrm{SiC}$ [10], and chemical vapor deposition (CVD). The chemical exfoliation method can produce graphene inexpensively, but the intrinsic properties of graphene produced by this method are very poor due to the vast amount of defects created during the harsh chemical treatment. On the other hand, the epitaxial growth on $\mathrm{SiC}$ produces graphene with much better intrinsic properties. However, the growth of graphene takes place on an expensive $\mathrm{SiC}$ substrate, making it unfeasible for large-scale production. CVD overcomes the drawbacks of these methods with its use of inexpensive substrates such as $\mathrm{Cu}$ and $\mathrm{Ni}$, where the dimensions of graphene are only limited by the size of the substrate placed in the system.

The very first CVD graphene system was reported in 2008/2009 [11,12]. At that time, single- and multi-layer graphene were grown on Ni substrates. Since then, the drive to create predominantly monolayer graphene has continued. By controlling different variables, researchers began to understand the conditions required for monolayer growth. Furthermore, the roll-to-roll (R2R) production of predominantly monolayer graphene film reaching 30 inches was achieved by Bae et al. [13], demonstrating the scale-up potential of CVD-grown graphene.

Since the predominant monolayer growth of graphene was realized, the research directions with regard to CVD graphene sought either to improve the quality of graphene or to make it more viable for mass production. To improve the quality of graphene, researchers 
mainly looked into improving its electrical aspects, as it was these aspects that made graphene such a popular subject. It was found that defects induced during the transfer processes [14] and the polycrystalline nature of CVD graphene hampered the electrical properties of graphene [15]. To make it more viable for mass production, approaches to eliminate the need for an etching step of a catalytic substrate, to enable the low-temperature growth of graphene, and to realize the aforementioned R2R production of graphene $[13,16,17]$ were investigated. Producing large samples of graphene film is relatively straightforward, as doing so can be achieved by placing a larger $\mathrm{Cu}$ substrate in the CVD system on which the graphene can grow. However, etching the large $\mathrm{Cu}$ substrate and handling the transfer of the resulting large graphene sheet are difficult, as the conventional poly(methyl methacrylate) (PMMA) support transfer method cannot be used.

The major obstacle hindering the integration of graphene into our everyday devices has less to do with graphene production methods and more to do with the quality of the graphene that is produced. As mentioned above, the $\mathrm{R} 2 \mathrm{R}$ production of 30 inch graphene sheets transferred to a target substrate has been achieved. However, the electron mobility of the graphene sheet was $\sim 5000 \mathrm{~cm}^{2} \mathrm{~V}^{-1} \mathrm{~S}^{-1}$. Considering that the electron mobility of suspended graphene is $\sim 200000 \mathrm{~cm}^{2} \mathrm{~V}^{-1} \mathrm{~S}^{-1}[18]$ and that the electron mobility of graphene on $\mathrm{SiO}_{2}$ is $\sim 40000 \mathrm{~cm}^{2} \mathrm{~V}^{-1} \mathrm{~S}$ [19], it can be seen that much room for improvement still exists.

As mentioned earlier, the main reason behind the poor mobility value is most likely the defects that are induced during the transfer and the polycrystallinity of CVD graphene; however, the latter source contributes more to a reduction in the electron mobility. As Yu et al. [15] clearly shows, after patterning electrodes on two neighboring graphene domains, the resistance peaks at the graphene grain boundaries (Fig. 1b). In addition, Zhou et al. [20] showed that after fabricating 55 different graphene fieldeffect transistors (FETs), higher mobility was observed in FETs fabricated with millimeter-sized graphene domains as compared to those made with polycrystalline graphene domains (Fig. 1c). Thus, it is logical that in order to improve the electrical properties of graphene, the need for a large graphene domain growth is crucial. It is unsurprising that many current reports on CVD graphene pivot around growing large-size graphene domains. This review will cover strategies proposed by various researchers to achieve large graphene domains and will outline the problem with current research trends in their efforts to tackle the problems caused by the polycrystallinity of CVD graphene.

\section{Basic Factors That Change the Nucleation of Graphene}

Before looking into methods proposed by researchers to grow large single-crystal graphene domains, the parameters that alter the nucleation of graphene will be investigated. In the CVD process, the controlled parameters are the substrate, the temperature, the pressure, and the gas composition. The growth time is another parameter that can be controlled in the CVD process, but it only affects the graphene coverage on the substrate. For this reason, this factor will be omitted here.
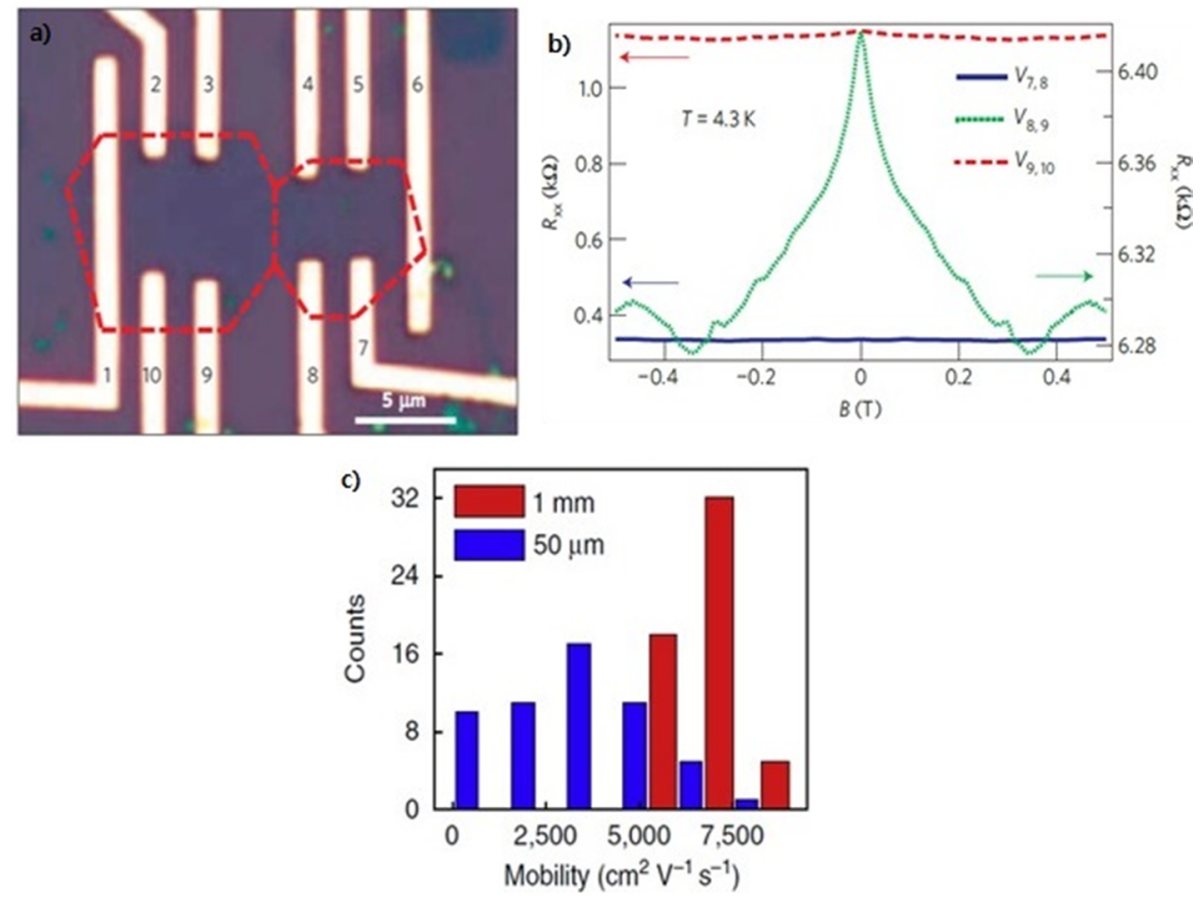

Fig. 1. (a) Electrodes patterned on neighboring graphene domains. (b) Graph showing the electrical resistance peaking at the inter-grain area (green line) compared to no electrical resistance change at the intra-grain area (blue and red lines). Reprinted with permission from [15]. Copyright $\odot$ 2011, Macmillan Publishers Ltd. (c) Histogram of the carrier mobility distribution of graphene field-effect transistors made on a single-crystalline domain (red) and on polycrystalline graphene (blue). Reprinted with permission from [20]. Copyright $\odot$ 2013, Macmillan Publishers Ltd. 
(a)

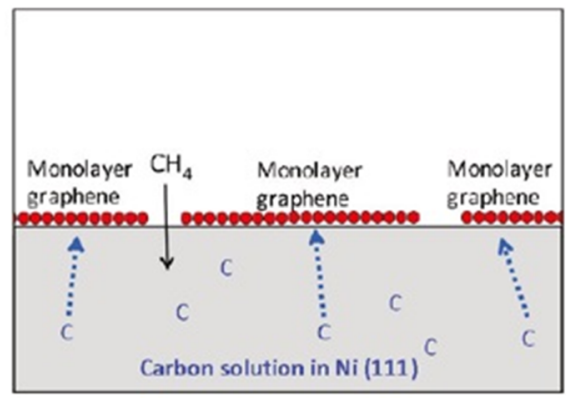

(b)

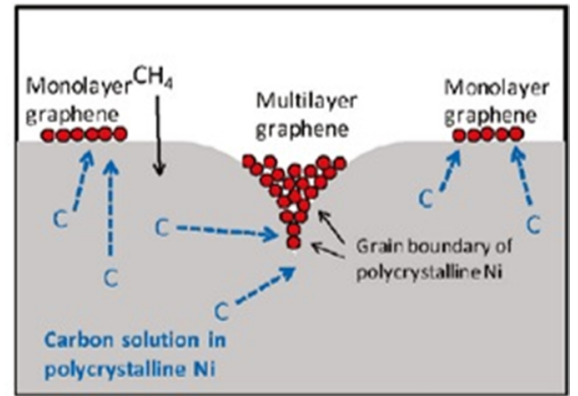

Fig. 2. Schematic showing why the complete monolayer growth of graphene is difficult when segregated growth occurs. Reprinted (adapted) with permission from [25]. Copyright $\odot$ 2010, American Chemical Society.

\subsection{Substrate}

The substrate acts as a catalyst on which graphene can grow. Therefore, it is unsurprising that the substrate has a major influence on the nucleation of graphene. CVD graphene growth on various transition metals has been reported, such as Pt [21], Ir [22], $\mathrm{Ni}[11,12]$, and $\mathrm{Cu}[23]$, with the latter two favored due to their low cost. There are two different growth mechanisms of graphene: segregation growth and surface growth [24]. Segregation growth generally takes place on metals with high levels of carbon solubility, such as Ni. At high temperatures, carbon can dissolve into the bulk of $\mathrm{Ni}$ and segregate to the surface during cooling. In addition, carbon tends to segregate more at the grain boundaries of Ni (Fig. 2). Due to this phenomenon, graphene growth on Ni generally results in patches of multilayer growth, and limiting the growth to one layer is difficult. On the other hand, surface growth takes place on metals with low levels of carbon solubility, such as $\mathrm{Cu}$. With $\mathrm{Cu}$, carbon does not precipitate into the bulk of the metal and growth is limited to surface diffusion; given that growth only occurs at the surface, the growth of graphene terminates once the $\mathrm{Cu}$ is covered with graphene in what is generally termed "the self-limiting effect." Therefore, once the $\mathrm{Cu}$ surface is covered with graphene, no further growth should take place. Thus, limiting the growth of graphene to a single layer becomes a much easier task. As a result, the most common type of substrate used for CVD graphene is a $\mathrm{Cu}$ substrate.

It should be noted that millimeter sized single-crystal graphene growth has been successfully achieved through segregation growth on $\mathrm{Ni}$ [26] and $\mathrm{Ru}$ [27]. However, additional processes were required to optimize the substrate, making it less desirable than $\mathrm{Cu}$.

\subsection{Temperature}

The most commonly reported temperatures for the monolayer growth of graphene on $\mathrm{Cu}$ range from $1000^{\circ} \mathrm{C}$ to $1050^{\circ} \mathrm{C}$. In this temperature range, complete coverage with predominantly monolayer growth is achieved for reasons that will be explained later in this section. Below this temperature range, incomplete coverage is observed even after a prolonged period of growth [28]. Also, the growth temperature can be as high as $1085^{\circ} \mathrm{C}$, at which the $\mathrm{Cu}$ substrate reaches its melting point. Higher growth temperatures are favored to produce

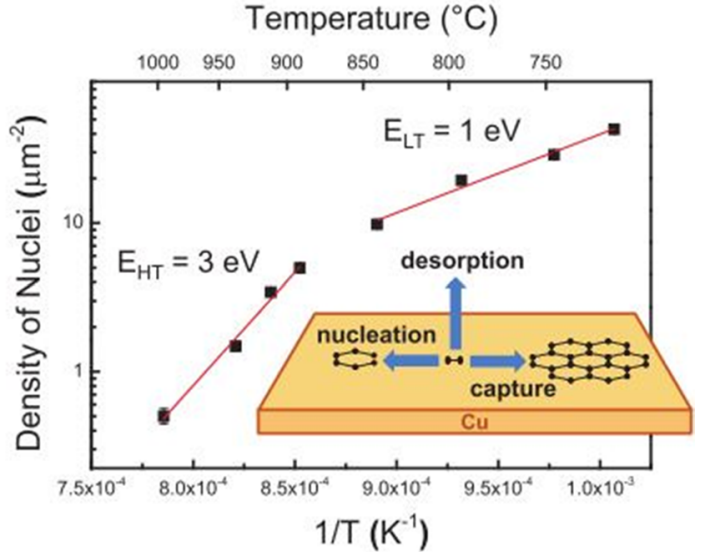

Fig. 3. Graph showing two temperature regimes with different activation energies. Reprinted (adapted) with permission from [28]. Copyright $₫$ 2012, American Chemical Society.

a large graphene domain size because increasing the growth temperature decreases the nucleation density of the graphene, allowing larger graphene domain growth (Fig. 3). At first glance, this may be slightly confusing, as one may expect the opposite to occur, as the activation energy for nucleation will be more easily met. However, it will be mentioned later that graphene prefers to nucleate in certain sites such as the grain boundaries, step edges, and other defect sites [29] and that increasing the temperature decreases the numbers of such sites. As a result, a reduction in the nucleation density is typically observed. Furthermore, the diffusion rate increases with the temperature; thus, the mobility of the carbon adatoms increases with the temperature. As the mobility of carbon adatoms increases, the probability that carbon adatoms will adhere to the existing graphene nucleus becomes greater than that of carbon adatoms creating a new graphene domain. An increase in the diffusion rate will also contribute to an increased growth rate of graphene domains, which in turn results in better growth coverage [30]. Kim et al. [28] also provides evidence that increasing the temperature does not lower the activation energy for nucleation. When calculating the nucleation activation energy $\left(E_{A}\right)$ in two temperature regimes, i.e., a low-temperature regime and a high-temperature regime, it was found that the $\mathrm{E}_{\mathrm{A}}$ value of graphene in the low-temperature regime $(\sim 1 \mathrm{eV})$ is lower than the $\mathrm{E}_{\mathrm{A}}$ in a high-temperature regime $(\sim 3 \mathrm{eV})$ 
[28]. This indicates that graphene can nucleate more easily in a low-temperature regime than in a high-temperature regime. For this reason, a high nucleation density is observed at low temperatures.

\subsection{Pressure}

CVD can be classified into the following two categories according to the pressure: low-pressure CVD (LPCVD) and atmospheric-pressure CVD (APCVD). In LPCVD, the chamber is pumped down and maintained in the mTorr range before the reactant gases are introduced. In APCVD, the chamber is purged with Ar before the reactants gases are introduced.

To understand how the nucleation mechanism changes depending on the pressure, the deposition sequence needs to be understood. The deposition sequence of the typical CVD process is as follows:

1) Diffusion in of reactants through the boundary layer

2) Adsorption of reactants on the substrate

3) Chemical reaction occurs

4) Desorption of the adsorbed species

5) Diffusion out of by-products

The pressure essentially governs step 1 of the CVD process. When the pressure decreases, the gas flow rate in the CVD system increases. This, in turn, decreases the boundary layer thickness, as it is governed by the following equation [31]:

$$
\begin{aligned}
& \Delta=\sqrt{x / R_{e}} \\
& R_{e}=\rho u_{x} / \mu .
\end{aligned}
$$

Here, $\Delta$ is the boundary layer thickness, $\mathrm{x}$ is the distance from the inlet, $R_{e}$ is the Reynold's number, $\rho$ is the fluid density, $u_{x}$ is the flow density, and $\mu$ is the viscosity.

As a result, at LP, the boundary layer becomes thin and the diffusion of the reactant gas through the boundary layer becomes rapid, while at a high pressure, the boundary layer becomes thick and the diffusion of the reactant gas through the boundary layer becomes slow. Therefore, the pressure essentially controls the growth kinetics of nucleation. When the diffusion of the reactant gas through the boundary layer is fast, the growth rate is said to be controlled by the surface reactant kinetics. On the other hand, when the pressure is high, the boundary layer is thick, resulting in the slower diffusion of the reactants onto the substrate. Here, the growth rate is said to be controlled by diffusion or mass transport [31]. The different growth kinetics depending on the pressure determines the growth shape of the graphene domains. Typically, when growing graphene via APCVD, the expected hexagonal domain shape is observed (Fig. 4c), while when growing graphene via LPCVD, a completely different four-lobe or six-lobe graphene domain is observed (Figs. 4a and b). However, one perplexing point is that, despite the fact that growth via LPCVD tends to be controlled by surface reactions, the four-/six-lobe domains show dendritic growth. Dendritic growth is a sign that diffusion-controlled growth is occurring [34]; therefore, some other factor must be contributing to the growth kinetics during LPCVD growth.

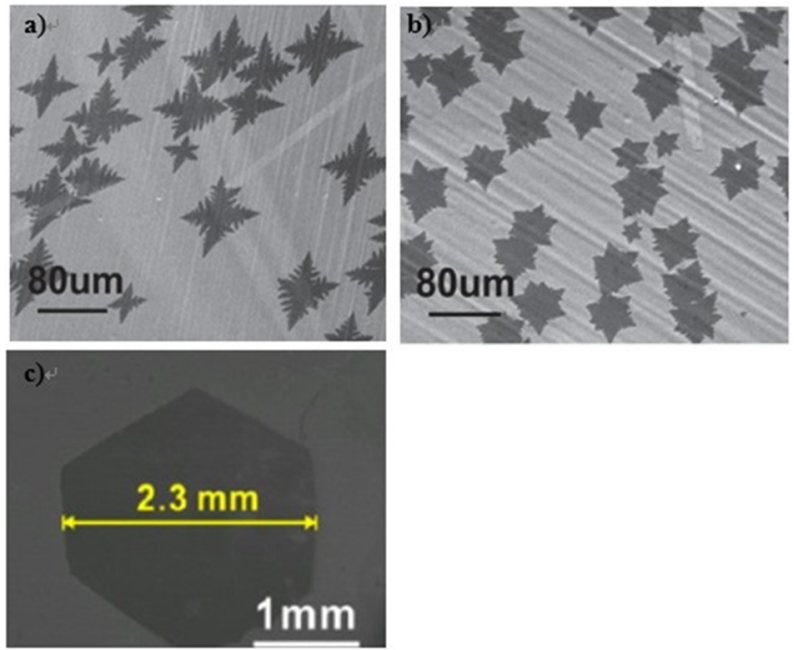

Fig. 4. (a and b) Scanning electron microscope (SEM) images of four-/ six-lobe flower graphene domains grown in the low pressure condition. Reprinted with permission from [33]. Copyright @ 2013, Wiley. (c) SEM image of hexagonal graphene domain grown in the atmospheric pressure condition. Reprinted (adapted) with permission from [32]. Copyright @ 2012, American Chemical Society.

\subsection{Gas ratio}

The $\mathrm{H}_{2}: \mathrm{CH}_{4}$ gas ratio has important implications not only during the nucleation of graphene but also on the growth rate of graphene. Thus, the role of each gas will be examined independently before an explanation of how the $\mathrm{H}_{2}: \mathrm{CH}_{4}$ ratio affects growth.

$\mathrm{CH}_{4}$ is the most commonly used carbon precursor due to its relative abundance and low cost. Although the use of $\mathrm{Cu}$ substrates leads to self-limiting behavior of graphene growth, proper control of the $\mathrm{CH}_{4}$ flow rate is still required. For any nucleation to occur, supersaturation is required [35]; thus, the $\mathrm{CH}_{4}$ partial pressure needs to exceed this supersaturation point before the growth of graphene can be observed. As the partial pressure of $\mathrm{CH}_{4}$ increases further, the number of carbon adatoms able to attach to the existing graphene domains increases, causing the graphene growth rate to increase as long as sufficient diffusion is occurring. Also, once the supersaturation point is reached, nucleation will either occur or not occur depending on whether the energy barrier can be overcome, which is independent of the $\mathrm{CH}_{4}$ partial pressure. Thus, increasing the $\mathrm{CH}_{4}$ partial pressure has no effect on the nucleation density past the supersaturation point. However, if the $\mathrm{CH}_{4}$ partial pressure is too high, bilayer and multilayer graphene may form [36]. Thus, a certain parameter exists for graphene growth on $\mathrm{Cu}$ substrates to be self-limiting, which seems to be closely related to the partial pressure of $\mathrm{CH}_{4}$. In the case of LPCVD growth, a bilayer graphene island is always located near the center of a larger single-layer graphene island, hinting at the possibility of the bilayer graphene island acting as a seed [37,38]. To understand the initial nucleation of graphene further, Kalbac et al. [37] altered a carbon precursor between ${ }^{12} \mathrm{CH}_{4}$ and ${ }^{13} \mathrm{CH}_{4}$ and analyzed the growth sequence using Raman spectroscopy. The two different isotopes could be distinguished in the Ra- 
man spectra according to the downshift of the ${ }^{13} \mathrm{CH}_{4}$ isotope peak due to its heavier mass. It was revealed that at the multilayer region, the top and bottom layers grew independently. As time passed, the bottom layer grew faster than the upper layer, resulting in a small multilayer graphene island in the middle of a large single-layer graphene island (on average, the top layer grow 10 times slower than the bottom layer). This was observed as carbon adatoms diffused rapidly through $\mathrm{Cu}$ to attach to the bottom layer while other carbon adatoms diffused slowly through the bottom graphene layer to attach to the top layer. Thus, as growth proceeded, it became increasingly more difficult for carbon adatoms to attach to the upper layers, resulting in a multilayer graphene island.

Hydrogen also plays an important role in the nucleation of graphene [39]. In fact, hydrogen plays an important role in all three stages of graphene growth: pre-growth, growth, and after growth. In the pre-growth stage, hydrogen removes any oxygen impurities from the Ar carrier gas as well as oxide impurities on the metal catalyst surface [38]. Also, when $\mathrm{CH}_{4}$ is pumped into the CVD system, hydrogen helps decompose $\mathrm{CH}_{4}$ into carbon atoms. The carbon atoms then absorb and diffuse through the $\mathrm{Cu}$ to form graphene. During the growth of graphene, hydrogen controls the size and morphology of the graphene domains. A study by Vlassiouk et al. [38] showed how changing the partial pressure of hydrogen affected the growth rate and growth shape of the graphene domains. When the partial pressure of hydrogen was increased while keeping the other parameters (temperature, $\mathrm{Ar}: \mathrm{CH}_{4}$ ratio, and growth time) constant, the average graphene domain size decreased and growth reached a certain terminal size. In addition, the shape of the graphene domain changed from flower-like at a lower partial pressure of hydrogen to a regular hexagon at a higher partial pressure of hydrogen. From these observations, it was concluded that hydrogen controls the size and morphology of graphene domains by acting as an etching reagent. After the growth of graphene, hydrogen is capable of etching graphene $[40,41]$. When continuous graphene on a $\mathrm{Cu}$ substrate is placed in a reducing atmosphere with no carbon precursor at a high temperature, holes begin to appear due to the etching effect of hydrogen. Interestingly, the shapes of these holes can be hexagonal [41] or fractal [40].

Altogether, the balance between $\mathrm{CH}_{4}$, which "creates" graphene, and $\mathrm{H}_{2}$, which "destroys" graphene, will dictate the growth rate of graphene. Thus, the fine tuning of the $\mathrm{H}_{2}: \mathrm{CH}_{4}$ ratio becomes important, not as much to control the nucleation density of graphene but to control the growth rate of graphene.

\section{Tactics to Reduce the Nucleation Density}

The previous section covered parameters that change the nucleation of graphene. However, how are these parameters implemented to grow large graphene domains? In order to achieve large graphene domains, the nucleation density needs to be suppressed such that "single-crystal" graphene grows as large as possible before its growth becomes terminated by the neighboring graphene domain, which in turn reduces the number of grain boundaries and hence improves the overall electrical properties of graphene.

\subsection{Substrate pretreatment}

The surface morphology of the $\mathrm{Cu}$ substrate plays an important role in the nucleation of graphene. For example, Liu et al. [42] show how graphene tends to nucleate along the direction of a rolling mark present on the $\mathrm{Cu}$ surface (Fig. 5e). Also, Han et al. [43] deliberately introduced scratch marks on $\mathrm{Cu}$ substrates and observed that graphene preferentially nucleated along these scratch marks (Fig. 5c), highlighting the importance of the substrate morphology on the nucleation of graphene. In order to limit the nucleation density, it is essential to eliminate these unwanted nucleation sites. One of the most profound surface features on a $\mathrm{Cu}$ substrate is a rolling mark introduced by cold rolling during the manufacturing process. The most common means of eliminating rolling marks is electro-polishing $[44,45]$. However, this has proved to be ineffective and insufficient to suppress the nucleation density because, although electro-polishing removes many surface irregularities, there are many other sites at which graphene can nucleate, preventing any significant reduction of the nucleation density. Nevertheless, the electro-polishing procedure improves the homogeneity of graphene and is considered as an important step to produce large graphene domains, with nearly all reports on CVD graphene on $\mathrm{Cu}$ substrates employing electro-polishing before synthesizing graphene.

Another pretreatment that is often employed is to extend the pre-growth annealing of the $\mathrm{Cu}$ substrate. As mentioned in Section 2, graphene has a tendency to nucleate at defect sites such as the grain boundaries of $\mathrm{Cu}$ and other impurity sites. Because long-term annealing at elevated temperatures promotes grain growth and the recrystallization of the $\mathrm{Cu}$ substrate, it reduces the number of possible nucleation sites for graphene $[36,46]$. Wang et al. [46] clearly showed that, by increasing the pregrowth annealing time from $1 \mathrm{~h}$ to $3 \mathrm{~h}$, the nucleation density of graphene was reduced, which in turn led to an increase in the graphene domain size. Yan et al. [32] also showed that the temperature at which annealing was performed was an important factor too. When the annealing temperature was $1060^{\circ} \mathrm{C}$, $1070^{\circ} \mathrm{C}$, and $1075^{\circ} \mathrm{C}$, the graphene domain size increased to $\sim 0.4, \sim 1$, and $\sim 1.8 \mathrm{~mm}$, respectively. This increase in the graphene domain size was attributed to the removal and reduction of nucleation sites. In addition, the recrystallization of the $\mathrm{Cu}$ substrate infers a change in the crystallographic orientation. Thus, various studies of how the $\mathrm{Cu}$ crystallographic orientation affects graphene nucleation have been reported [47-49]. Electron back-scatter diffraction mapping was employed to determine the crystal orientation in a $\mathrm{Cu}$ foil, and numerous $\mathrm{Cu}$ facets, such as the $\mathrm{Cu}(100), \mathrm{Cu}(310), \mathrm{Cu}(410), \mathrm{Cu}$ (632), and $\mathrm{Cu}$ (110) facets were observed. However, coverage of the $\mathrm{Cu}$ (111) facet dominates, as it has the lowest surface energy [50]. There have been various reports that the graphene preferentially nucleates and grows faster at a particular facet. For example, Wofford et al. [51] suggested that the growth front of graphene on the $\mathrm{Cu}(100)$ facet advances faster than that on other facets. In addition, they observed that the growth direction is deflected when the growth front comes across pinning sites or neighboring graphene islands. However Wood et al. [52] observed that the $\mathrm{Cu}(100)$ surface causes slow multilayer growth, while $\mathrm{Cu}$ (111) promotes raid monolayer growth. The cause of this observation was that $\mathrm{Cu}(111)$ has a smaller lattice mismatch with the 

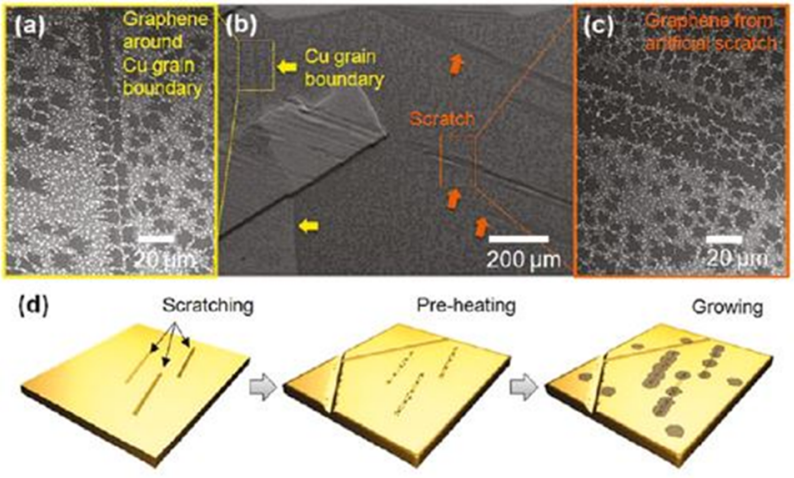

(e)

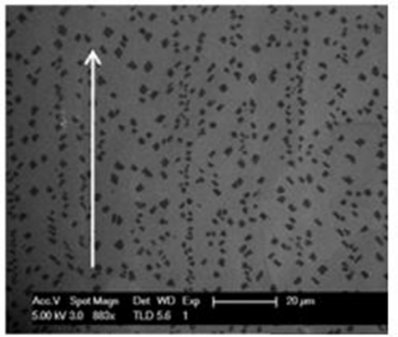

Fig. 5. (a-c) Scanning electron microscope (SEM) images showing graphene preferentially nucleating along the Cu grain boundary and an intentionally introduced scratch mark. (d) Depiction of graphene nucleating at the scratch mark shown in Figs. $5 \mathrm{~b}$ and c. Reprinted (adapted) with permission from [43]. Copyright @ 2011, American Chemical Society. (e) SEM image showing graphene preferentially nucleating along the rolling marks of $\mathrm{Cu}$; the white arrow indicates the direction of the rolling marks. Reprinted with permission from [42]. Copyright @ 2011, Elsevier.

graphene domain, resulting in faster adsorption of the carbon species [53], while an adatom-exchange mediated mechanism [54] and a higher level of carbon adsorption energy [53] in the $\mathrm{Cu}(100)$ lead to slow diffusion. These conflicting reports show that there are other factors that influence the preferential nucleation of graphene on certain $\mathrm{Cu}$ facets, indicating that more research is needed in this area.

In another aspect, Kim et al. [55] demonstrated that the $\mathrm{Cu}$ crystal orientation plays an important role in the distribution of nano-ripples on graphene surfaces. They noted that when comparing the current mappings of graphene grown on the $\mathrm{Cu}$ (111) facet and the $\mathrm{Cu}(100)$ facet, the $\mathrm{Cu}(111)$ facet shows a homogeneous current distribution while $\mathrm{Cu}(100)$ shows degraded conductivity. This degraded conductivity is linked to the nanoripple on the graphene surface. The reason why nano-ripples form on $\mathrm{Cu}$ (100) and not (111) was found to be linked to the fact that $\mathrm{Cu}$ (111) has a similar in-plane lattice constant with graphene while other facets such as $\mathrm{Cu}(100)$ have greater lattice mismatches. When incorporating this type of lattice mismatch with a high temperature during the growth of graphene, surface roughening occurs, which is directly translated to the graphene during the transfer process.

Nevertheless, millimeter-sized graphene domains have successfully been grown on polycrystalline $\mathrm{Cu}$ substrates, demonstrating that there are other factors that prevail and that the polycrystallinity of $\mathrm{Cu}$ may not be as daunting of an issue as initially considered.
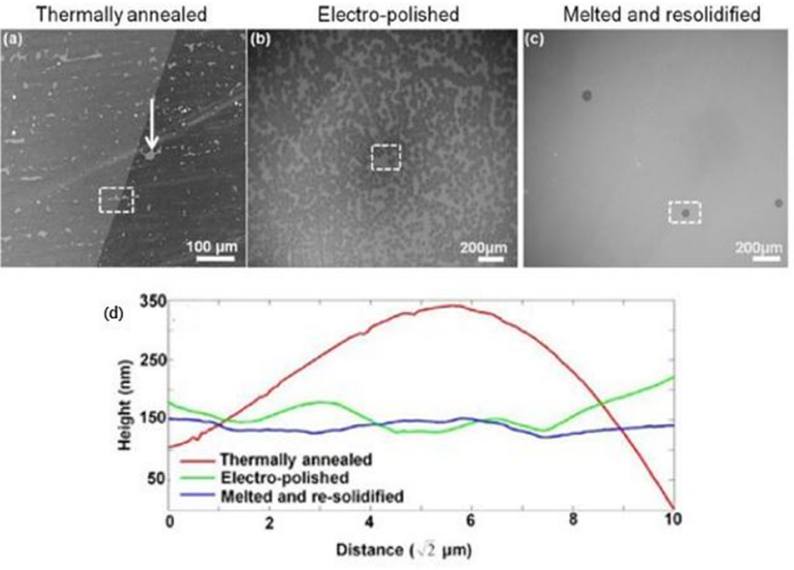

Fig. 6. (a-c) Scanning electron microscope (SEM) images showing the difference in the nucleation density of graphene between (a) thermally annealed $\mathrm{Cu}$, (b) electro-polished $\mathrm{Cu}$, and (c) melted and resolidified $\mathrm{Cu}$. (d) Typical atomic force microscopy line profile of a thermally annealed, electro-polished and melted, and resolidified Cu substrate. Reprinted (adapted) with permission from [57]. Copyright @ 2013, American Chemical Society.

\subsection{Melting the substrate}

For some researchers, annealing is not enough, and they took a step forward by completely melting the $\mathrm{Cu}$ substrate altogether. Wu et al. [56] reported the growth of graphene at the melting temperature of $\mathrm{Cu}\left(1090^{\circ} \mathrm{C}\right)$, while Moshin et al. [57] reported the growth of graphene on resolidified $\mathrm{Cu}$. Though the growth of graphene on liquid $\mathrm{Cu}$ is a unique idea, graphene domains are limited to $200 \mu \mathrm{m}$, and the Raman spectra suggest that graphene is a multi-layer material in nature. This can be explained by the fact that liquid $\mathrm{Cu}$ is unstable (a convection current may exist), making uniform graphene growth difficult. On the other hand, a very different result was noted during the growth of graphene on resolidified $\mathrm{Cu}$. The nucleation density was vastly reduced when compared to that of annealed and electro-polished $\mathrm{Cu}$ (Figs. 6a-c). Also, $\sim 1 \mathrm{~mm}$ single-crystal graphene was achieved. By melting and resolidifying the $\mathrm{Cu}$ completely, a surface morphology smoother than that of the electro-polished substrate was obtained (Fig. $6 \mathrm{~d})$. In addition, recrystallization of the entire substrate removed defect sites more effectively than high-temperature annealing. It would be interesting to determine whether the cooling rate affects the nucleation density, as a longer cooling time will result in larger $\mathrm{Cu}$ crystals and, thus, fewer grain boundaries. However, to the best of our knowledge, no such report exists today. Despite the realization of millimeter-sized single-crystal graphene, some may argue about whether the melting and resolidifying of $\mathrm{Cu}$ substrates can be applied on an industrial scale. As one can imagine, melting and resolidifying $\mathrm{Cu}$ substrates up to a wafer-scale size may lead to uneven thickness solidification, affecting the homogeneity of the graphene nucleation process. Furthermore, having to load the $\mathrm{Cu}$ on top of a tungsten substrate adds to the cost, as does having to incorporate a time-consuming etching step of a tungsten substrate into the transfer procedure of graphene. 
Table 1. Summary of the parameters used for growth of millimeter-sized graphene domains

\begin{tabular}{|c|c|c|c|c|c|c|c|}
\hline Reference & $\mathrm{AP} / \mathrm{LP}$ & $\begin{array}{c}\text { Growth temp } \\
\left({ }^{\circ} \mathrm{C}\right)\end{array}$ & $\begin{array}{c}\text { Pre-growth } \\
\text { annealing time }\end{array}$ & Growth time & $\begin{array}{c}\mathrm{H}_{2}: \mathrm{CH}_{4} \text { ratio } \\
(\mathrm{sccm})\end{array}$ & $\begin{array}{l}\text { Mobility } \\
\left(\mathrm{cm}^{2} / \mathrm{Vs}\right)\end{array}$ & $\begin{array}{l}\text { Single crystal } \\
\text { size }(\mathrm{mm})\end{array}$ \\
\hline$[20]$ & LP & 1070 & $5 \min$ & $48 \mathrm{~h}$ & a) & 16000 & 5 \\
\hline$[32]$ & $\mathrm{CP}$ (108 torr) & 1077 & $7 \mathrm{~h}$ & $125 \mathrm{~min}$ & $70: 0.15$ & $7900-11000$ & 2.3 \\
\hline$[57]$ & AP & 1075 & $\mathrm{x}$ & $5 \mathrm{~h}$ & $100: 0.46$ & $\mathrm{x}$ & 1 \\
\hline$[58]$ & AP & 1050 & $90 \mathrm{~min}$ & $\mathrm{x}$ & $21: 15^{\text {b) }}$ & $\mathrm{x}$ & 5.9 \\
\hline$[64]$ & AP & 1050 & $60 \mathrm{~min}$ & $80 \mathrm{~min}$ & $2: x^{c)}$ & $5000-8000$ & 1.2 \\
\hline
\end{tabular}

AP: atmospheric pressure, LP: low pressure, CP: controlled pressure.

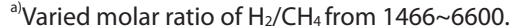

${ }^{\text {b) }}$ Fifteen sccm of 500 ppm methane diluted in $\mathrm{Ar}$.

c) Used polystyrene as carbon source.

\subsection{Non-reducing pre-growth atmosphere}

Another strategy used to limit the nucleation density and, hence, grow large graphene domains is to heat the substrate in a non-reducing atmosphere. Generally, during the heating of a CVD system to the growth temperature, both hydrogen and argon are flown into the CVD system - argon to create an inert atmosphere and hydrogen to remove oxide impurities in the Ar carrier gas and on the $\mathrm{Cu}$ substrate. However, simply by removing hydrogen from the heating step, a vast reduction of the nucleation density can be observed [20,58]. Using this strategy, Gan and Luo [58] reported graphene domain sizes as large as $5.9 \mathrm{~mm}$ and a nucleation density as low as 0.6 nuclei $/ \mathrm{mm}^{2}$. A closer examination showed that an Ar-only environment produced a rough but uniform surface with copper oxide nanoparticles randomly distributed on the surface. These copper oxide nanoparticles were reduced to $\mathrm{Cu}$ during $\mathrm{Ar}: \mathrm{H}_{2}$ pre-growth annealing, where graphene preferred to nucleate. Hydrogen is well known to be capable of reducing native oxide impurities on $\mathrm{Cu}$ substrates, such as $\mathrm{CuO}$ and $\mathrm{Cu}_{2} \mathrm{O}$, to pure $\mathrm{Cu}$ [59]. However, why graphene prefers to nucleate in reduced $\mathrm{Cu}$ is not well understood. Gan and Luo [58] explained that graphene tended to nucleate in reduced $\mathrm{Cu}$ because it produced nanoparticles with heights as high as $50 \mathrm{~nm}$. As these sites protrude mostly out of the $\mathrm{Cu}$ surface, the likelihood of carbon adatoms being captured increases. Moreover, increasing the pre-growth annealing time increases the number of reduced-oxide nanoparticles, whereas the number of particles taller than $20 \mathrm{~nm}$ decreases, and only those which are taller than $20 \mathrm{~nm}$ act as nucleation sites [58]. Thus, although increasing the annealing time increases the number of oxide nanoparticles, those which contribute to graphene nucleation decrease.

Zhou et al. [20] used a similar strategy, relying on a non-reducing atmosphere to reach the growth temperature. Zhou et al. [20] noted that a $\mathrm{Cu}_{2} \mathrm{O}$ layer exists on a copper foil rather than on copper oxide nanoparticles. Moreover, because graphene tends to nucleate on the $\mathrm{Cu}$ surface rather than on the $\mathrm{Cu}_{2} \mathrm{O}$ layer, having an initial oxide layer greatly limits the nucleation density. By optimizing the $\mathrm{H}_{2}: \mathrm{CH}_{4}$ ratio and using LP rather than AP, graphene domains of $\sim 5 \mathrm{~mm}$ and nucleation density levels of 4 nuclei $/ \mathrm{cm}^{2}$ were achieved. It should also be noted that nuclei densities at this magnitude are only seen when the growth temperature is reached in a non-reducing atmosphere. Therefore, oxide must be playing a pivotal role in controlling the nucleation density. Nevertheless, scarcely any research on how oxide impacts the growth of graphene has been carried out. In fact, to the best of our knowledge, only one paper by Hao et al. [60] used the oxygen impurity level as a control factor during graphene nucleation. By measuring the oxide impurity level on $\mathrm{Cu}$ substrates and varying the oxygen exposure times, it was observed that increasing the oxygen exposure time decreases the graphene nucleation density to as low as $\sim 0.01$ nuclei $/ \mathrm{mm}^{2}$, leading to a graphene domain size of $\sim 1 \mathrm{~cm}$ in diameter, the largest ever reported, to the best of our knowledge. However, one major drawback was that a growth time of $12 \mathrm{~h}$ was required to grow a centimeter-sized graphene domain.

\subsection{Pressure and other tactics}

In Section 2, we covered how the pressure effects the nucleation of graphene, but not much was mentioned on how it affects the nucleation density of graphene. Vlassiouk et al. [61] observed how the pressure affects the nucleation density of graphene. It appeared that LPCVD resulted in a lower nucleation density $\left(\sim 10^{2} \mathrm{~mm}^{2}\right)$ than APCVD $\left(\sim 10^{3} \mathrm{~mm}^{2}\right)$. However, one slight flaw that can arise when comparing the nucleation density levels of APCVD and LPCVD is that, because the growth kinetics differs, the growth rates will also differ. Therefore, a direct comparison of the nucleation density with the same growth times may not reflect the nucleation density of graphene but instead the growth speed of graphene. Therefore, rather than observing only the nucleation density of graphene, the graphene domain size was also examined by Yan et al. [32]. By adding a metering valve to a CVD system that could be manipulated from $1 \mathrm{mTorr}$ to 1500 torr, the relationship between the pressure and the graphene domain size was investigated. However, despite the wide pressure control range, growth at only 8.2 torr and 108 torr was reported. In short, growth at 108 torr resulted in larger graphene domains of $2.3 \mathrm{~mm}$, only after a lengthy growth time that exceeded $2 \mathrm{~h}$ and an annealing time of $7 \mathrm{~h}$.

Another indirect effect pressure has is the sublimation of $\mathrm{Cu}$. Generally, graphene CVD takes place at $1000^{\circ} \mathrm{C}$, which is close to the melting point of $\mathrm{Cu}\left(1084^{\circ} \mathrm{C}\right.$ [62]). Although the melting of $\mathrm{Cu}$ does not take place during the CVD of graphene, orange- 
brownish tainting on the quartz tube surface is often seen, which is evidence of $\mathrm{Cu}$ sublimation [63]. Vlassiouk et al. [61] noted that the sublimation of $\mathrm{Cu}$ may impact the nucleation density of graphene. As $\mathrm{Cu}$ sublimes, any carbon species absorbed onto the $\mathrm{Cu}$ will evaporate together, increasing the desorption of carbon, which in turn reduces the nucleation density.

Another tactic that can be employed is initially to raise the carbon concentration above the supersaturation point so that some nucleation will occur and then decrease the carbon concentration to below the supersaturation point so that further nucleation is inhibited while the growth of the existing graphene domain continues. Wu et al. [64] used this strategy to achieve a nucleation density of $\sim 100$ nuclei/ $/ \mathrm{cm}^{2}$ and a domain size of 1.2 $\mathrm{mm}$. In addition, poly-styrene (PS) was used as a carbon source instead of conventional $\mathrm{CH}_{4}$. The reason for using PS was that, according to the author, the C-H bond in PS $(292-305 \mathrm{~kJ} / \mathrm{mol})$ is weaker than that in $\mathrm{CH}_{4}(410 \mathrm{~kJ} / \mathrm{mol})$.

\section{Addressing the Issue of Homogeneity}

Despite the efforts to reduce the nucleation density, random distributions of nucleation sites are inevitable (Fig. 7a). This causes the nucleation density to vary from area to area within the same $\mathrm{Cu}$ substrate. This can lead to a new problem in which too much variation of the graphene domain size can result in inhomogeneous graphene in which some areas have outstanding electric mobility (because clusters of large graphene domains exist and, hence, less scattering occurs), while other areas of the same sample have lower electric mobility. To avoid this phenomenon, seeding growth of graphene may be a solution. To the best of our knowledge, only two reports show arrays of graphene domain nucleation through a seeding mechanism $[15,56]$. With nucleation seed arrays, inhomogeneous graphene can be avoided as long as graphene nucleation starts at the nucleation
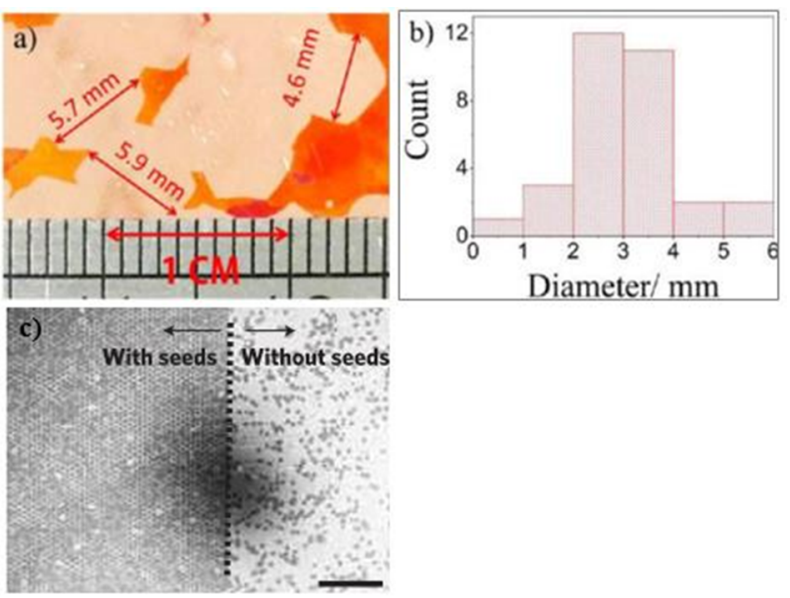

Fig. 7. (a) Large graphene domains on a Cu substrate made visible by oxidization in air at $200^{\circ} \mathrm{C}$ for $1 \mathrm{~min}$, (b) graphene domain size distribution in (a). Reprinted (adapted) with permission from [58]. Copyright 2013, American Chemical Society. (c) Difference in the graphene nucleation distribution between seeded growth and non-seeded growth conditions. The scale bar corresponds to $200 \mu \mathrm{m}$. Reprinted with permission from [15]. Copyright @ 2011, Macmillan Publishers Ltd. seed arrays. Then, the nucleation density will be even throughout the entire area, and large variations in the electric mobility of the sample will likely be minimized. Yu et al. [15] achieved seeded growth by patterning pre-grown graphene through CVD. Fig. 7c depicts a comparison of the nucleation distribution between seeded growth and non-seeded growth conditions. Evidently, seeded growth shows homogenous distributions of graphene domains, and by adjusting the spacing between each seed, an array of large graphene domains may be a possibility. The downside of the seeded method proposed by Yu et al. [15] is that two growth runs are required to form the final product. $\mathrm{Wu}$ et al. [65] proposed another seeding method in which arrays of PMMA dots were patterned on $\mathrm{Cu}$ substrates through electronbeam lithography (E-beam lithography). Graphene preferentially nucleated at the PMMA dots because, locally, it had a higher concentration of carbon, allowing the supersaturation point to be reached more easily. One drawback was that the nucleation behavior was similar to that noted with LPCVD with a low $\mathrm{H}_{2} \mathrm{CH}_{4}$ ratio, where a multilayer region existed at the center of the graphene domains.

\section{Outlook \& Future Considerations}

Ultimately, in order to incorporate CVD graphene into highend electronic devices, a large single-crystal graphene domain is needed. This is evident from electronic devices adopting singlecrystal silicon rather than polycrystalline silicon due to its higher performance. The trend shows that, by increasing the grain size of graphene domains, its property improves as well. Therefore, it is inevitable that growing large-size single-crystal graphene domains is important. However, vastly sacrificing the growth rate of graphene to achieve a large graphene domain will not help graphene become implemented in mainstream electronics, especially when growth and annealing processes lasting dozens of hours are necessary. For example, domain growth of $1 \mathrm{~mm}$ of graphene may be a great accomplishment, but if it requires a growth time of $48 \mathrm{~h}$, it is unrealistic to be adapted for industrial-scale production [20]. Table 1 shows that most graphene domains over $1 \mathrm{~mm}$ require lengthy annealing and growth times. In addition, full graphene coverage is not achieved, even after those long hours. In this regard, researchers appear to get too carried away to create large single-crystal graphene domains, and they deviate too far from realizing a single-crystal graphene domain for mass production. Nevertheless, understanding the factors that influence the production of a large graphene domain size is invaluable, and these can always be altered to make mass production more feasible. It should always be kept in mind that the advantage of the CVD process is that large-area monolayer graphene can be grown, especially when the R2R potential has already been established [17].

\section{Conclusion}

This review presents a current overview of research trends related to CVD graphene. Despite the realization of the R2R production of graphene films reaching 30 inches in length, the electronic properties were degraded due to the polycrystalline nature 
of the graphene produced. Thus, the need for large single-crystal graphene domains arose. To achieve large single-crystal graphene domains, the nucleation density had to be suppressed such that the growth did not terminate due to neighboring graphene domains. Basic factors that affected nucleation were looked into before the tactics used by researchers were reviewed. Despite the achievement of a relatively large domain size, it is difficult to employ the proposed strategies for mass production, as the growth and annealing times required to grow these large graphene domains are unfeasible. Also, the problem of an inhomogeneous distribution of these large graphene domains causing local variation of the properties within the same sample will need to be investigated in the future.

\section{Acknowledgment}

This research was supported by the Mid-career Researcher Program thorough the National Research Foundation of Korea funded by the Ministry of Science, ICT \& Future planning (NRF-2010-0029244).

\section{References}

[1] Novoselov KS, Geim AK, Morozov SV, Jiang D, Zhang Y, Dubonos SV, Grigorieva IV, Firsov AA. Electric field effect in atomically thin carbon films. Science, 306, 666 (2004). http://dx.doi. org/10.1126/science.1102896.

[2] Choi YY, Kang SJ, Kim HK, Choi WM, Na SI. Multilayer graphene films as transparent electrodes for organic photovoltaic devices. Sol Energy Mater Sol Cells, 96, 281 (2012). http://dx.doi. org/10.1016/j.solmat.2011.09.031.

[3] Kim KS, Zhao Y, Jang H, Lee SY, Kim JM, Kim KS, Ahn JH, Kim P, Choi JY, Hong BH. Large-scale pattern growth of graphene films for stretchable transparent electrodes. Nature, 457, 706 (2009). http://dx.doi.org/10.1038/nature07719.

[4] Wang X, Zhi L, Müllen K. Transparent, conductive graphene electrodes for dye-sensitized solar cells. Nano Lett, 8, 323 (2007). http://dx.doi.org/10.1021/nl072838r.

[5] Matyba P, Yamaguchi H, Eda G, Chhowalla M, Edman L, Robinson ND. Graphene and mobile ions: the key to all-plastic, solutionprocessed light-emitting devices. ACS Nano, 4, 637 (2010). http:// dx.doi.org/10.1021/nn9018569.

[6] Lemme MC, Echtermeyer TJ, Baus M, Kurz H. A graphene fieldeffect device. IEEE Electron Device Lett, 28, 282 (2007). http:// dx.doi.org/10.1109/LED.2007.891668.

[7] Shao Y, Wang J, Wu H, Liu J, Aksay IA, Lin Y. Graphene based electrochemical sensors and biosensors: a review. Electroanalysis, 22, 1027 (2010). http://dx.doi.org/10.1002/elan.200900571.

[8] Schedin F, Geim AK, Morozov SV, Hill EW, Blake P, Katsnelson MI, Novoselov KS. Detection of individual gas molecules adsorbed on graphene. Nat Mater, 6, 652 (2007). http://dx.doi.org/10.1038/ nmat1967.

[9] Stankovich S, Dikin DA, Dommett GHB, Kohlhaas KM, Zimney EJ, Stach EA, Piner RD, Nguyen ST, Ruoff RS. Graphenebased composite materials. Nature, 442, 282 (2006). http://dx.doi. org/10.1038/nature04969.

[10] Berger C, Song Z, Li T, Li X, Ogbazghi AY, Feng R, Dai Z, March- enkov AN, Conrad EH, First PN, de Heer WA. Ultrathin epitaxial graphite: $2 \mathrm{~d}$ electron gas properties and a route toward graphenebased nanoelectronics. J Phys Chem B, 108, 19912 (2004). http:// dx.doi.org/10.1021/jp040650f.

[11] Reina A, Jia X, Ho J, Nezich D, Son H, Bulovic V, Dresselhaus MS, Kong J. Large area, few-layer graphene films on arbitrary substrates by chemical vapor deposition. Nano Lett, 9, 30 (2008). http://dx.doi.org/10.1021/nl801827v

[12] Yu Q, Lian J, Siriponglert S, Li H, Chen YP, Pei SS. Graphene segregated on Ni surfaces and transferred to insulators. Appl Phys Lett, 93, 113103 (2008). http://dx.doi.org/10.1063/1.2982585.

[13] Bae S, Kim H, Lee Y, Xu X, Park JS, Zheng Y, Balakrishnan J, Lei T, Ri Kim H, Song YI, Kim YJ, Kim KS, Ozyilmaz B, Ahn JH, Hong BH, Iijima S. Roll-to-roll production of 30-inch graphene films for transparent electrodes. Nat Nano, 5, 574 (2010). http:// dx.doi.org/10.1038/nnano.2010.132.

[14] Choi WJ, Chung YJ, Park S, Yang CS, Lee YK, An KS, Lee YS, Lee JO. A simple method for cleaning graphene surfaces with an electrostatic force. Adv Mater, 26, 637 (2014). http://dx.doi org/10.1002/adma.201303199.

[15] Yu Q, Jauregui LA, Wu W, Colby R, Tian J, Su Z, Cao H, Liu Z, Pandey D, Wei D, Chung TF, Peng P, Guisinger NP, Stach EA, Bao J, Pei SS, Chen YP. Control and characterization of individual grains and grain boundaries in graphene grown by chemical vapour deposition. Nat Mater, 10, 443 (2011). http://dx.doi.org/10.1038/ nmat3010.

[16] Kobayashi T, Bando M, Kimura N, Shimizu K, Kadono K, Umezu N, Miyahara K, Hayazaki S, Nagai S, Mizuguchi Y, Murakami Y, Hobara D. Production of a 100-m-long high-quality graphene transparent conductive film by roll-to-roll chemical vapor deposition and transfer process. Appl Phys Lett, 102, 023112 (2013) http://dx.doi.org/10.1063/1.4776707.

[17] Ryu J, Kim Y, Won D, Kim N, Park JS, Lee EK, Cho D, Cho SP, Kim SJ, Ryu GH, Shin HAS, Lee Z, Hong BH, Cho S. Fast synthesis of high-performance graphene films by hydrogen-free rapid thermal chemical vapor deposition. ACS Nano, 8, 950 (2013). http://dx.doi.org/10.1021/nn405754d.

[18] Bolotin KI, Sikes KJ, Jiang Z, Klima M, Fudenberg G, Hone J, Kim P, Stormer HL. Ultrahigh electron mobility in suspended graphene. Solid State Commun, 146, 351 (2008). http://dx.doi. org/10.1016/j.ssc.2008.02.024

[19] Chen JH, Jang C, Xiao S, Ishigami M, Fuhrer MS. Intrinsic and extrinsic performance limits of graphene devices on $\mathrm{SiO}_{2}$. Nat Nano, 3, 206 (2008). http://dx.doi.org/10.1038/nnano.2008.58.

[20] Zhou H, Yu WJ, Liu L, Cheng R, Chen Y, Huang X, Liu Y, Wang Y, Huang Y, Duan X. Chemical vapour deposition growth of large single crystals of monolayer and bilayer graphene. Nat Commun, 4, 2096 (2013). http://dx.doi.org/10.1038/ncomms3096.

[21] Sutter P, Sadowski JT, Sutter E. Graphene on Pt(111): growth and substrate interaction. Phys Rev B, 80, 245411 (2009). http://dx.doi org/10.1103/PhysRevB.80.245411.

[22] Coraux J, N`Diaye AT, Busse C, Michely T. Structural coherency of graphene on $\operatorname{Ir}(111)$. Nano Lett, 8, 565 (2008). http://dx.doi org/10.1021/nl0728874.

[23] Li X, Cai W, An J, Kim S, Nah J, Yang D, Piner R, Velamakanni A, Jung I, Tutuc E, Banerjee SK, Colombo L, Ruoff RS. Large-area synthesis of high-quality and uniform graphene films on copper foils. Science, 324, 1312 (2009). http://dx.doi.org/10.1126/science. 1171245 
[24] Li X, Cai W, Colombo L, Ruoff RS. Evolution of graphene growth on $\mathrm{Ni}$ and $\mathrm{Cu}$ by carbon isotope labeling. Nano Lett, 9, 4268 (2009). http://dx.doi.org/10.1021/n1902515k.

[25] Zhang Y, Gomez L, Ishikawa FN, Madaria A, Ryu K, Wang C, Badmaev A, Zhou C. Comparison of graphene growth on singlecrystalline and polycrystalline ni by chemical vapor deposition. J Phys Chem Lett, 1, 3101 (2010). http://dx.doi.org/10.1021/ jz1011466.

[26] Iwasaki T, Park HJ, Konuma M, Lee DS, Smet JH, Starke U. Longrange ordered single-crystal graphene on high-quality heteroepitaxial Ni thin films grown on $\mathrm{MgO}(111)$. Nano Lett, 11, 79 (2010). http://dx.doi.org/10.1021/nl102834q.

[27] Pan Y, Zhang H, Shi D, Sun J, Du S, Liu F, Gao HJ. Highly ordered, millimeter-scale, continuous, single-crystalline graphene monolayer formed on Ru (0001). Adv Mater, 21, 2777 (2009). http://dx.doi.org/10.1002/adma.200800761.

[28] Kim H, Mattevi C, Calvo MR, Oberg JC, Artiglia L, Agnoli S, Hirjibehedin CF, Chhowalla M, Saiz E. Activation energy paths for graphene nucleation and growth on $\mathrm{Cu}$. ACS Nano, 6, 3614 (2012). http://dx.doi.org/10.1021/nn3008965.

[29] Robertson AW, Warner JH. Hexagonal single crystal domains of few-layer graphene on copper foils. Nano Lett, 11, 1182 (2011). http://dx.doi.org/10.1021/n1104142k.

[30] Ambrosi A, Bonanni A, Sofer Z, Pumera M. Large-scale quantification of CVD graphene surface coverage. Nanoscale, 5, 2379 (2013). http://dx.doi.org/10.1039/C3NR33824J.

[31] Bhaviripudi S, Jia X, Dresselhaus MS, Kong J. Role of kinetic factors in chemical vapor deposition synthesis of uniform large area graphene using copper catalyst. Nano Lett, 10, 4128 (2010). http:// dx.doi.org/10.1021/nl102355e

[32] Yan Z, Lin J, Peng Z, Sun Z, Zhu Y, Li L, Xiang C, Samuel EL, Kittrell C, Tour JM. Toward the synthesis of wafer-scale single-crystal graphene on copper foils. ACS Nano, 6, 9110 (2012). http://dx.doi. org/10.1021/nn303352k

[33] Wu Y, Hao Y, Jeong HY, Lee Z, Chen S, Jiang W, Wu Q, Piner RD, Kang J, Ruoff RS. Crystal structure evolution of individual graphene islands during CVD growth on copper foil. Adv Mater, 25, 6744 (2013). http://dx.doi.org/10.1002/adma.201302208.

[34] Bartelt NC, McCarty KF. Graphene growth on metal surfaces. MRS Bull, 37, 1158 (2012). http://dx.doi.org/10.1557/mrs.2012.237.

[35] Venables JA, Spiller GDT, Hanbucken M. Nucleation and growth of thin films. Rep Prog Phys, 47, 399 (1984). http://dx.doi. org/10.1088/0034-4885/47/4/002.

[36] Trinsoutrot P, Rabot C, Vergnes H, Delamoreanu A, Zenasni A, Caussat B. High quality graphene synthesized by atmospheric pressure CVD on copper foil. Surf Coat Technol, 230, 87 (2013). http://dx.doi.org/10.1016/j.surfcoat.2013.06.050.

[37] Kalbac M, Frank O, Kavan L. The control of graphene double-layer formation in copper-catalyzed chemical vapor deposition. Carbon, 50, 3682 (2012). http://dx.doi.org/10.1016/j.carbon.2012.03.041.

[38] Vlassiouk I, Regmi M, Fulvio P, Dai S, Datskos P, Eres G, Smirnov $\mathrm{S}$. Role of hydrogen in chemical vapor deposition growth of large single-crystal graphene. ACS Nano, 5, 6069 (2011). http://dx.doi. org/10.1021/nn201978y.

[39] Losurdo M, Giangregorio MM, Capezzuto P, Bruno G. Graphene CVD growth on copper and nickel: role of hydrogen in kinetics and structure. Phys Chem Chem Phys, 13, 20836 (2011). http://dx.doi. org/10.1039/C1CP22347J.

[40] Geng D, Wu B, Guo Y, Luo B, Xue Y, Chen J, Yu G, Liu Y. Fractal etching of graphene. J Am Chem Soc, 135, 6431 (2013). http:// dx.doi.org/10.1021/ja402224h.

[41] Zhang Y, Li Z, Kim P, Zhang L, Zhou C. Anisotropic hydrogen etching of chemical vapor deposited graphene. ACS Nano, 6, 126 (2011). http://dx.doi.org/10.1021/nn202996r.

[42] Liu W, Li H, Xu C, Khatami Y, Banerjee K. Synthesis of highquality monolayer and bilayer graphene on copper using chemical vapor deposition. Carbon, 49, 4122 (2011). http://dx.doi. org/10.1016/j.carbon.2011.05.047.

[43] Han GH, Güneş F, Bae JJ, Kim ES, Chae SJ, Shin H-J, Choi JY, Pribat D, Lee YH. Influence of copper morphology in forming nucleation seeds for graphene growth. Nano Lett, 11, 4144 (2011). http://dx.doi.org/10.1021/n1201980p.

[44] Zhang B, Lee WH, Piner R, Kholmanov I, Wu Y, Li H, Ji H, Ruoff RS. Low-temperature chemical vapor deposition growth of graphene from toluene on electropolished copper foils. ACS Nano, 6 2471 (2012). http://dx.doi.org/10.1021/nn204827h.

[45] Luo Z, Lu Y, Singer DW, Berck ME, Somers LA, Goldsmith BR, Johnson ATC. Effect of substrate roughness and feedstock concentration on growth of wafer-scale graphene at atmospheric pressure. Chem Mater, 23, 1441 (2011). http://dx.doi.org/10.1021/ cm1028854

[46] Wang H, Wang G, Bao P, Yang S, Zhu W, Xie X, Zhang WJ. Controllable synthesis of submillimeter single-crystal monolayer graphene domains on copper foils by suppressing nucleation. J Am Chem Soc, 134, 3627 (2012). http://dx.doi.org/10.1021/ja2105976.

[47] Rasool HI, Song EB, Allen MJ, Wassei JK, Kaner RB, Wang KL, Weiller BH, Gimzewski JK. Continuity of graphene on polycrystalline copper. Nano Lett, 11, 251 (2010). http://dx.doi.org/10.1021/ nl1036403.

[48] Edwards RS, Coleman KS. Graphene film growth on polycrystalline metals. Acc Chem Res, 46, 23 (2012). http://dx.doi org/10.1021/ar3001266.

[49] Murdock AT, Koos A, Britton TB, Houben L, Batten T, Zhang T, Wilkinson AJ, Dunin-Borkowski RE, Lekka CE, Grobert N. Controlling the orientation, edge geometry, and thickness of chemical vapor deposition graphene. ACS Nano, 7, 1351 (2013). http:// dx.doi.org/10.1021/nn3049297.

[50] Chatain D, Wynblatt P, Rohrer GS. Anisotropic phenomena at interfaces in bismuth-saturated copper. Scripta Mater, 50, 565 (2004). http://dx.doi.org/10.1016/j.scriptamat.2003.11.058.

[51] Wofford JM, Nie S, McCarty KF, Bartelt NC, Dubon OD. Graphene islands on $\mathrm{Cu}$ foils: the interplay between shape, orientation, and defects. Nano Lett, 10, 4890 (2010). http://dx.doi.org/10.1021/ nl102788f

[52] Wood JD, Schmucker SW, Lyons AS, Pop E, Lyding JW. Effects of polycrystalline $\mathrm{Cu}$ substrate on graphene growth by chemical vapor deposition. Nano Lett, 11, 4547 (2011). http://dx.doi. org/10.1021/nl201566c.

[53] Zhang W, Wu P, Li Z, Yang J. First-principles thermodynamics of graphene growth on $\mathrm{Cu}$ surfaces. J Phys Chem C, 115, 17782 (2011). http://dx.doi.org/10.1021/jp2006827.

[54] Hansen L, Stoltze P, Jacobsen KW, Nørskov JK. Self-diffusion on copper surfaces. Phys Rev B, 44, 6523 (1991). http://dx.doi. org/10.1103/PhysRevB.44.6523.

[55] Kim DW, Lee J, Kim SJ, Jeon S, Jung HT. The effects of the crystalline orientation of $\mathrm{Cu}$ domains on the formation of nanoripple arrays in CVD-grown graphene on Cu. J Mater Chem C, 1, 7819 (2013). http://dx.doi.org/10.1039/C3TC31717J. 
[56] Wu YA, Fan Y, Speller S, Creeth GL, Sadowski JT, He K, Robertson AW, Allen CS, Warner JH. Large single crystals of graphene on melted copper using chemical vapor deposition. ACS Nano, 6 , 5010 (2012). http://dx.doi.org/10.1021/nn3016629.

[57] Mohsin A, Liu L, Liu P, Deng W, Ivanov IN, Li G, Dyck OE, Duscher G, Dunlap JR, Xiao K, Gu G. Synthesis of millimeter-size hexagon-shaped graphene single crystals on resolidified copper. ACS Nano, 7, 8924 (2013). http://dx.doi.org/10.1021/nn4034019.

[58] Gan L, Luo Z. Turning off hydrogen to realize seeded growth of subcentimeter single-crystal graphene grains on copper. ACS Nano, 7, 9480 (2013). http://dx.doi.org/10.1021/nn404393b.

[59] Yamukyan MH, Manukyan KV, Kharatyan SL. Copper oxide reduction by hydrogen under the self-propagation reaction mode. J Alloys Compd, 473, 546 (2009). http://dx.doi.org/10.1016/j.jallcom.2008.06.031.

[60] Hao Y, Bharathi MS, Wang L, Liu Y, Chen H, Nie S, Wang X, Chou H, Tan C, Fallahazad B, Ramanarayan H, Magnuson CW, Tutuc E, Yakobson BI, McCarty KF, Zhang YW, Kim P, Hone J, Colombo L, Ruoff RS. The role of surface oxygen in the growth of large single-crystal graphene on copper. Science, 342, 720 (2013). http:// dx.doi.org/10.1126/science. 1243879 .
[61] Vlassiouk I, Smirnov S, Regmi M, Surwade SP, Srivastava N, Feenstra R, Eres G, Parish C, Lavrik N, Datskos P, Dai S, Fulvio P. Graphene nucleation density on copper: fundamental role of background pressure. J Phys Chem C, 117, 18919 (2013). http://dx.doi. org/10.1021/jp4047648.

[62] Karabacak T, DeLuca JS, Wang PI, Eyck GAT, Ye D, Wang GC, Lu TM. Low temperature melting of copper nanorod arrays. J Appl Phys, 99, 064304 (2006). http://dx.doi.org/10.1063/1.2180437.

[63] Kidambi PR, Ducati C, Dlubak B, Gardiner D, Weatherup RS, Martin MB, Seneor P, Coles H, Hofmann S. The parameter space of graphene chemical vapor deposition on polycrystalline $\mathrm{Cu}$. J Phys Chem C, 116, 22492 (2012). http://dx.doi.org/10.1021/ jp303597m.

[64] Wu T, Ding G, Shen H, Wang H, Sun L, Jiang D, Xie X, Jiang $\mathrm{M}$. Triggering the continuous growth of graphene toward millimeter-sized grains. Adv Funct Mater, 23, 198 (2013). http://dx.doi. org/10.1002/adfm.201201577.

[65] Wu W, Jauregui LA, Su Z, Liu Z, Bao J, Chen YP, Yu Q. Growth of single crystal graphene arrays by locally controlling nucleation on polycrystalline $\mathrm{Cu}$ using chemical vapor deposition. Adv Mater, 23, 4898 (2011). http://dx.doi.org/10.1002/adma.201102456. 